\title{
BMJ Open What are parents' perspectives on psychological empowerment in the MMR vaccination decision? A focus group study
}

\author{
Marta Fadda, ${ }^{1}$ Elisa Galimberti, ${ }^{1}$ Valter Carraro, ${ }^{2}$ Peter J Schulz ${ }^{1}$
}

To cite: Fadda M,

Galimberti E, Carraro V, et al. What are parents'

perspectives on psychological empowerment in the MMR vaccination decision? A focus group study. BMJ Open 2016;6:e010773.

doi:10.1136/bmjopen-2015010773

- Prepublication history and additional material is available. To view please visit the journal (http://dx.doi.org/ 10.1136/bmjopen-2015010773).

Received 8 December 2015 Revised 15 February 2016 Accepted 14 March 2016

CrossMark

\begin{abstract}
${ }^{1}$ Faculty of Communication Sciences, Institute of Communication and Health, Università della Svizzera Italiana, Lugano, Switzerland 2Department of Hygiene and Public Health, Azienda Autonoma Sanitaria della Provincia di Trento, Trento, Italy
\end{abstract}

Correspondence to Marta Fadda;

marta.fadda@usi.ch

\section{ABSTRACT}

Objectives: Most developed countries do not have compulsory immunisation requirements, but instead issue recommendations. Although parents are expected to make an informed, autonomous (ie, empowered) decision regarding their children's vaccinations, there is no evidence about how parents' interpret this demand nor on the latitude of their decision-making. The goal of this study is to gain insights from parents residing in a low measlesmumps-rubella (MMR) uptake area on what constitutes feelings of empowerment in the decision they have to make on their child's MMR vaccination.

Design: A qualitative study employing focus group interviews.

Setting: 11 vaccination centres and hospitals in the Province of Trento, Italy.

Participants: 24 mothers and 4 fathers of children for whom the MMR vaccination decision was still pending participated in 6 focus groups.

Results: Autonomy and competence were salient themes in relation to empowerment, and were further connected with beliefs regarding legal responsibility and ethics of freedom concerning the decision, parents' relationship with the paediatrician (trust), feelings of relevance of the decision and related stress, and seeking, avoidance, or fear of vaccination-related information. Competence was interpreted as medical knowledge and information-seeking skills, but it was also related to the extent parents perceived the paediatrician to be competent.

Conclusions: Since parents' interpretation of empowerment goes beyond mere perceptions of being informed and autonomous and differs across individuals, it is important that this construct be correctly interpreted and implemented by best practice, for instance by explicitly adopting a relational conception of autonomy. Knowing whether parents want to make an empowered decision and what their information and autonomy needs are might help health professionals adapt their communication about immunisation, and promote parental perception of making an informed, autonomous decision.

\section{Strengths and limitations of this study}

- The study provides insights into the significance parents attribute to empowerment in the measles-mumps-rubella (MMR) vaccination decision-making.

- It examines the perspectives of parents about empowerment in the MMR vaccination decisionmaking and highlights tensions of opinion.

- It explores the drivers of the MMR vaccination decision-making of parents residing in a low MMR vaccination-covered area in Italy.

- The self-selected nature of our sample might have resulted in recruitment bias, as parents with favourable attitudes towards the MMR vaccination may be more likely to accept invitations to participate in a study and share their opinion.

- Our recruitment strategy, which targeted parents attending a number of vaccination centres to have their children' immunised against diphtheria, tetanus and pertussis (DTaP), might have prevented us from reaching those who are highly opposed to the MMR immunisations and other vaccinations such as DTaP.

\section{INTRODUCTION}

The call for patient empowerment and patient-centred care that is pervading in almost all health contexts has also involved parents as decisionmakers on behalf of their children. The prominent principle of preserving and promoting individuals' autonomous choices and actions has been translated, in the immunisation context, into the principle of protecting and promoting parents' ability to make and act on free, informed decisions, resulting from 'capable and uninfluenced deliberation'. ' With ethical attention being increasingly drawn to the vaccination decision, current vaccination programmes in most developed countries have now called for parents' willingness to make an intentional, informed and 
autonomous decision. This is transferred, for practical purposes, into the widespread use of informed consent forms disclosing the risks as well as the benefits of the immunisation $^{2}$ and the policy to make or keep vaccination non-compulsory. ${ }^{3}{ }^{4}$ Thus, public health authorities tacitly interpret empowerment as an ethically justified process that follows the acknowledgment of the official recommendations and eventually leads to a decision that is both free from controlling influences and not mandated by law. However, there is little concern with understanding how to practically recognise, safeguard and promote empowerment in the vaccination decision, beyond the mere use of informed consent and nonmandatory immunisations. ${ }^{1}$ How parents have interpreted and to what extent they have adopted the demands put on them when choosing whether or not to vaccinate their children has only been explored marginally. ${ }^{5}$ Furthermore, while several predictors are known, ${ }^{6}$ such as risk perception, ${ }^{7-11}$ beliefs and attitudes, ${ }^{12-16}$ safety concerns, ${ }^{17-19}$ trust $^{10} \quad 20-25$ and social norms, ${ }^{26}$ parents' perceptions about their empowerment in the vaccination decision have so far been almost exclusively neglected as possible drivers of their vaccination behaviour, despite previous work suggesting the relevance of empowerment-related dimensions such as self-efficacy and self-determination in this health decision. ${ }^{5}$

\section{Psychological empowerment}

Although being recognised as a key element in the current shift towards patient-centred healthcare, there is little agreement on what constitutes psychological empowerment. ${ }^{27}$ Empowerment received increasing attention during the 1980s, when it was applied to the health context. Zimmerman ${ }^{28}$ proposes a definition of psychological empowerment as a construct that consists of three inter-related dimensions: (1) an intrapersonal dimension consisting of cognitive appraisals of control, competence, motivation and self-esteem; (2) an interactional dimension consisting of critical skills and knowledge; and (3) a behavioural dimension reflecting participatory, change-oriented behaviours in formal and informal contexts and organisations.

Spreitzer, ${ }^{29} 30$ on the other hand, sees psychological empowerment as an intrinsic motivational construct of the individual and separates Zimmerman's concept of intrapersonal empowerment into four dimensions or cognitions: (1) meaningfulness (the extent to which what one does is perceived as being important), (2) competence (one's perceived competence to carry out an action), (3) impact (the perception of making a difference through a certain action) and (4) selfdetermination (the extent to which what we do is perceived as autonomous).

In the context of health, empowerment has been found to be related to positive health outcomes, ${ }^{31}$ more active decision-making, ${ }^{32}$ increased knowledge, ${ }^{33}$ better self-management ${ }^{34}$ and more satisfaction with one's decision. $^{32}$

\section{Aim of the study}

Psychological empowerment may vary greatly across individuals and contexts, and fluctuate over time. ${ }^{35}$ A single definition and measure cannot therefore be generalised to multiple settings. ${ }^{36}$ The aim of the current study is to explore parents' perspectives on empowerment in the context of the measles-mumps-rubella (MMR) vaccination decision in a low MMR covered area, building on similar previous work ${ }^{5}$ and grounding in the conceptualisation of psychological empowerment as a set of four subdimensions proposed by Spreitzer: ${ }^{29} 30$ (1) meaningfulness, referring to the degree to which an individual thinks that making a vaccination decision regarding his or her child is an important issue; (2) competence, referring to the degree to which an individual feels able to make a sound vaccination decision; (3) impact, referring to the degree to which an individual feels that making a decision over the vaccination can generate a number of outcomes; (4) self-determination or autonomy, referring to the degree to which individuals think that their vaccination decision is free from controlling influences. For this purpose, we decided to conduct qualitative focus groups to maximise parents' discussion, since we considered the vaccination decision as a socially constructed experience based on interactions with other individuals. ${ }^{37}$ The decision-making process focus of the present study is specific to the context of the MMR vaccination decision due to a number of features that make this vaccination unique compared with other childhood vaccinations. Not only is MMR at the centre of the autism controversy ${ }^{38}$ but also, since it is made of live attenuated viruses, administering this vaccine might be seen by parents as the closest thing to causing a natural infection. $^{39}$ Furthermore, MMR coverage is decreasing in several developed countries and postponing this vaccination may have serious consequences for future outbreaks. ${ }^{40}$

\section{METHODS}

\section{Recruitment}

We recruited our focus group participants through the 11 vaccination centres of the Province of Trento, Italy. MMR coverage in this area is $84.21 \%$ despite the $95 \%$ required threshold to achieve herd immunity, ${ }^{41}$ making it one of the seven regions in Italy where more than $15 \%$ of children have not been vaccinated with the first dose of MMR by the age of 2 years. To be included in the study, parents had to have at least one child aged less than 1 year or for whom an MMR vaccination decision was still pending, and be residing in Italy. Italy's MMR vaccination schedule envisages two doses, which are given when the child is 12-15 months and 5-6 years old, respectively. ${ }^{42}$ In the Province of Trento, childhood vaccinations are administered in the public health and vaccination centres located in each of the 11 local areas that the Province is divided into. Parents are invited to the vaccination through a written letter; in case of 
no-show for the scheduled appointment, parents are sent two more letters of solicitation. Vaccinations are usually administered by trained nurses and health professionals who are supervised by a preventive medicine doctor in the vaccination centres.

Parents were handed an invitation to the study by the nurses during their vaccination appointment for the first or second dose of the diphtheria, tetanus and pertussis (DTaP) vaccination, which are administered when the child is aged 3 and 5 months, respectively. Diphtheria and tetanus vaccinations are mandatory in Italy (parents refusing it for their children may be subject to a fine). The invitation stated the objectives of the study, the interview process and a guarantee of confidentiality. Parents filled out the invitation with their contact details and returned it in a box placed in the waiting room. Invitations were collected and we contacted each participant either by phone or by email, to arrange the focus group meetings.

\section{Data collection}

Focus groups were held in a private setting within the local health authority buildings between March and May 2015. Each focus group lasted $1 \mathrm{~h}$ and one/two facilitators and one recorder were present. Participants sat in a circle in order to promote discussion. Before starting the interview, we obtained consent from the participants and informed them about the scope of the study, its duration, the right to withdraw from the study at any point and the reward that would be offered to them at the end of the focus group. After the interview, we asked the parents to fill out a brief survey with questions on vaccination knowledge $e^{43}$ and sociodemographic variables relative to both parents (origin, age, education, number and age of children) and gave them a skin care product for their child together with a debriefing letter.

A list of semistructured questions aimed at probing parents on meanings and interpretations associated with empowerment in the MMR vaccination decision was developed by the research team on the basis of the literature on psychological empowerment, on Spreitzer's empowerment model and on previous health-related empowerment scales ${ }^{8}{ }^{9}$ (see online supplementary appendix 1). Questions were open-ended and broad in order to understand parents' decision-making processes as well as their experiences and feelings. We kept the grid as flexible as possible to allow a free-flowing discussion.

We recorded each interview, using a digital voice recorder, and transcribed them verbatim. We reached saturation of the data at six focus groups, when we decided that additional interviews would not yield new data, but only confirm what had already been found. ${ }^{44}$

\section{Data analysis}

To guarantee the quality of the findings and to generate as many insights as possible, which would be merged or further distinguished at a later stage, two coders (MF and EG) independently performed an inductive thematic analysis ${ }^{45}$ of the transcripts. We proceeded according to the following stages: we initially read the transcripts several times to become familiar with the content, manually underlined meaningful quotes, gradually grouped them under a number of labels, organised all labels hierarchically and created links among labels to channel them into broader themes. To validate the results, comparisons between the two coders took place in-between each of the aforementioned stages, so that the preliminary themes, labels and quotations were constantly discussed, and interpretation discordances resolved through dialogue and by constantly referring to the transcripts. All themes were then compared with Spreitzer's empowerment conceptualisation into four subdimensions $^{29} 30$ to check for correspondences. Both the transcription and the analysis of the interviews were conducted in the original language (Italian).

\section{RESULTS}

\section{Characteristics of the sample}

We sent 1000 invitations to the 11 vaccination centres, distributing the number according to their size. Of the total amount of invitations that were sent, we received 128 invitation forms completed with the participant's details. Eligibility of the recruited parents was checked by the vaccination centre nurses; therefore, the invitation form was only handed to eligible participants. We contacted all 128 parents, of whom 67 were available to participate in the focus groups. Finally, 28 parents (dropout rate 58\%) took part in six focus groups, each including four to six participants. All participants filled out a paper-and-pencil survey on vaccination knowledge and sociodemographic variables. Most participants were mothers $(86 \%)$ and had Italian nationality $(82 \%)$. The high share of non-Italians (against $8.3 \%$ immigrants living in Italy) ${ }^{46}$ ensured diversity in terms of origin in our sample. The average age was 36.5 years $(\mathrm{SD}=5.5$; range $=28-48$ ), while in terms of education about half of the sample had completed university (46\%), approximately half had completed secondary education $(46 \%)$ and only two participants either had frequented a professional school or did not continue studying after obligatory school. Most parents (64\%) had more than one child, meaning that they had made an MMR vaccination decision for at least one older child. Vaccination knowledge was found to be on average $6.15(\mathrm{SD}=2.06$; range $=0-9$ ), where 9 was the highest possible score. See table 1 for an overview of participants' characteristics.

\section{Issues of empowerment}

In general, parents held varying views about empowerment in relation to the MMR vaccination decision, with most participants affirming that their views apply to all paediatric vaccinations and are not restricted to the MMR immunisation. When asked about their reasons for participation, most parents reported that they hoped 


\begin{tabular}{|c|c|}
\hline & $(\mathrm{N}=28)$ \\
\hline \multicolumn{2}{|l|}{ Sex } \\
\hline Women & $\mathrm{n}=24(86 \%)$ \\
\hline Men & $n=4(14 \%)$ \\
\hline Age & $\mathrm{M}=36.5 ; \mathrm{SD}=5.5 ;$ range $=28-48$ \\
\hline \multicolumn{2}{|l|}{ Origin } \\
\hline Italy & $\mathrm{n}=23(82 \%)$ \\
\hline Other EU & $n=3(11 \%)$ \\
\hline Other non-EU & $\mathrm{n}=2(7 \%)$ \\
\hline \multicolumn{2}{|l|}{ Education } \\
\hline University & $n=13(46 \%)$ \\
\hline Professional school & $\mathrm{n}=1(4 \%)$ \\
\hline Secondary school & $n=13(46 \%)$ \\
\hline Obligatory school & $\mathrm{n}=1(4 \%)$ \\
\hline \multicolumn{2}{|l|}{ Number of children } \\
\hline 1 child & $n=10(36 \%)$ \\
\hline 2-5 children & $n=18(64 \%)$ \\
\hline \multicolumn{2}{|l|}{ Children's age } \\
\hline$<6$ months & $\mathrm{n}=2(7 \%)$ \\
\hline$<12$ months & $\mathrm{n}=25(89 \%)$ \\
\hline$>2$ years & $\mathrm{n}=1(4 \%)$ \\
\hline Vaccination knowledge & $\mathrm{M}=6.15 ; \mathrm{SD}=2.06 ;$ range $=0-9$ \\
\hline \multicolumn{2}{|c|}{ Attitude towards the MMR vaccination } \\
\hline Undecided & $\mathrm{n}=9(32 \%)$ \\
\hline In favour & $\mathrm{n}=19(68 \%)$ \\
\hline
\end{tabular}

to find answers to their questions about childhood vaccinations, to understand why some parents do not want to vaccinate, to meet other parents to discuss the topic and know what they think, and because they considered providing information and helping research a civic duty. The majority of the participants found that vaccination was a public good, and thus deserves discussion and meetings.

Generally, about one-quarter of the parents reported they felt uncomfortable in making the MMR vaccination decision due to safety concerns, uncertainty and low perceived competence, while the large majority reported to be confident with their choice. Autonomy was related to competence, which was interpreted as medical knowledge and information-seeking skills, but it was also related to the extent parents perceived the paediatrician to be competent and to the quality of their relationship with the paediatrician. Parents held varying beliefs regarding the legal responsibility (the possibility to be held responsible in case of vaccination-related or disease-related adverse events) and freedom of the decision, diverse feelings of relevance of the decision and related stress, as well as different orientations towards vaccination-related information.

\section{Competence as a key to autonomy}

The majority of the participants reported that, to feel autonomous in the MMR vaccination decision, it is crucial to possess adequate competence. Competence was interpreted as medical knowledge as well as a set of skills related to finding, objectively assessing and finally understanding vaccination-related information:

[Autonomy means] gathering information, not letting myself being influenced by other mothers. I got information at the prenatal classes, where there was a pediatrician. Then I asked my own pediatrician. Then those from the vaccination center came in. [...] Autonomy in this sense, I documented myself. (Mother, 32, Italian)

You look at different websites, different forums and different arguments. What really needs to be looked at. [...] Then you have to be objective, you have to step out of the thing, say, and try to analyze what you've just read. Rationally. (Mother, 28, Italian)

Very few participants, however, stressed that it is impossible to reach complete autonomy because parents can never have the appropriate skills to make a decision by themselves, but always need to rely on medical professionals.

I think it's impossible to be autonomous for us, as parents, if we are not doctors. We do not have the skills to make such a decision. It's far better to rely on someone who does that as a job, who can explain to you the pros and cons, the reasons...Then you, as a parent, can make your own decision, but then it's your own personal decision which is not based on the scientific method. (Mother, 48, Italian)

The large majority of parents reported feeling competent and, consequently, autonomous, when they could also obtain vaccination-related information and guidance from an expert whom they could trust, for example, the child's paediatrician.

[I feel competent]...when I have a consultation with someone competent that I can trust. (Mother, 31, Italian)

[To feel autonomous] I completely rely on the pediatrician. She is also the one who cared for me until I was 14 , so I really trust her. If I notice that she is calm, I also get calmer. (Mother, 28, Italian)

In this context, about half of the participants reported that they tended to decide what the paediatrician suggested if they perceived there was affinity between them in terms of opinion.

I'm afraid that...I would chose the opinion that is closer to mine, 'cause in the end one already has an opinion...I think I would go for...I would not be able to be completely objective "cause in the end you feel fully in tune with someone if that idea appeals to you most. (Mother, 38 , Italian)

Parents also listed a number of characteristics the ideal paediatrician should possess to be considered competent and trustworthy, and to establish a good 
relationship, namely availability, empathy, interest and attentiveness. Few participants complained that their paediatricians lacked these skills and that, as a result, they had a poor relationship with them.

When he dedicates me time, when I understand he is listening to me and is answering exactly what I am asking. (Mother, 30, Italy)

\section{Autonomy as legal responsibility and freedom}

When asked about their interpretation of autonomy in the MMR vaccination decision, the majority of the participants reported that having a free choice on their child's immunisation was equivalent to being asked to assume the responsibility for any potential positive or negative consequences that might result from vaccinating or not vaccinating their child. Parents differed in their views on this theme, with the majority reporting that they felt being appointed as a role not belonging to them. These participants considered that making the final decision on the vaccination was a matter of legal responsibility, which parents should not assume since they lack the medical skills needed to make an informed decision. Referring again to competence as being vital to autonomy, they reported that their medical understanding was inadequate to enable an autonomous, responsible choice.

For me autonomy means responsibility, and you are not always as informed or as prepared as a doctor would be, so...well, you can have the freedom to choose yes or not, but...I don't always feel up to the situation. (Mother, 38, Italian)

Only a few participants reported that they were willing to assume full responsibility for the decision, even in case of negative consequences due to the vaccination or the disease.

You cannot blame yourself for everything, but you have to take on your responsibilities. (Mother, 40, Italian)

Almost all parents also reported that being autonomous in the vaccination decision is a matter of freedom. Parents had opposite views on this theme, with half of them seeing autonomy as a dangerous right that parents should not have. This group of participants included those who were not willing to assume the legal responsibility of their MMR vaccination decision.

I do not find this autonomy fair. I noticed that several diseases spreading around in the schools could easily be prevented by vaccinating. In my opinion, those should be obligatory. After all, I cannot decide by myself. (Mother, 31, Italian)

The other half of the parents, while stressing the ethical aspects of being free in the vaccination decision, reported that it is morally important that all parents are free to make the final decision on their child's MMR vaccination.
The free choice on everything seems fair to me. It is reasonable to me that nothing is compulsory any longer. However, if this free choice means that, out of 100 children, 60 to 70 vaccinate and 30 do not, then we should re-evaluate the situation. (Mother, 48, Italy)

\section{Information orientation}

The majority of parents reported that being autonomous in the MMR vaccination is a matter of actively looking for information, expecting the information to be delivered by the paediatrician or the health authorities, or simply avoiding any information. Half of the participants described themselves as active information seekers who try to consult as many sources as possible, stating that it is up to parents to look for information themselves.

If one wants information, he or she should get out and find it. (Mother, 46, Italy)

About a quarter of the participants, rather, expected the health authorities, medical professionals and vaccination centres to provide them with easy and accessible information prior to their appointment for the vaccination, stating that it is not up to parents to look for vaccination-related information.

It's up to the pediatrician to start by providing information. They take it for granted that we know all the things, but instead...this is not always the case. (Mother, 30, Non EU)

In this context, about a quarter of the participants reported that fear of the information that could be found (possible side effects of the MMR vaccination, including autism) and lack of medical knowledge prevented them from looking for information on vaccinations and led them to avoid the information given by other parents.

I tend to stay away from the websites 'cause you read all sorts of things. It happened to me once, then I worried and started to do, to think much worse than it was, so I don't even go and look at it! (Mother, 42, Italian)

\section{Relevance of the decision and related stress}

For the majority of the participants, confidence in the MMR vaccination decision-making was related to the relative importance of this decision. Almost all parents reported that the vaccination decision is something you just make, it is not among the priorities and does not cause stress.

For me it's among the last ones. Partly because I had health issues... and then because it was a decision that I had already made, in the sense that I knew I just had to do it, so that was not such a hard decision. (Mother, 30, Other EU)

A small minority reported that making the decision is among the most important decisions, as it becomes a 
stressful task that consumes time and energy, and creates tensions in the couple. These parents also reported to have a poor relationship with their child's paediatrician.

Deciding for MMR has really been a moment of tension between me and my husband...I remember. It was not like deciding whether to breastfeed or not. That was my decision. We really went through a period of tension. (Mother, 38, Italy)

\section{DISCUSSION}

\section{Main findings}

The aim of this focus group study was to explore the construct of psychological empowerment in the MMR vaccination decision among a sample of parents residing in a low MMR coverage area in Italy. Issues of autonomy and competence largely dominate our results, and appear to be strictly inter-related. Autonomy, interpreted as both responsibility and freedom, seems to largely depend on parents' competence and this, in turn, on their relationship with the child's healthcare provider, the relevance of investing in the decision and their information-seeking behaviours.

First, the large majority of the participants reported they could feel competent and autonomous not only when having the appropriate knowledge and information-seeking skills but also when they could rely on a competent and trustworthy paediatrician. Other studies found that trust in the paediatrician can be a relatively important factor influencing parents' vaccination decision ${ }^{47-49}$ and, considering that according to the Italian system children are administered the vaccine by a nurse in a vaccination centre and not by their paediatrician, it should be further explored whether trust in the vaccine provider as well could compensate for parents' perceived lack of competence. Few parents also stated they would rather listen to a paediatrician with vaccination opinions similar to theirs. These findings confirm a large set of literature on the importance of the child's provider on parents' vaccination deci$\operatorname{sion}^{50-54}$ and on the tendency many parents have to choose a provider with vaccine beliefs similar to their own. ${ }^{55}$ The results are also in line with the theory of relational or conscientious autonomy, which assumes that our sense of autonomy depends on other individuals' influence on our lives. ${ }^{56}$ The theory stresses that "social interactions can affect autonomy not only by influencing individuals' health-related preferences and choices but also their self-identities, self-evaluations, and capabilities for autonomy". ${ }^{56}$ Our findings suggest that parents might report that they can never be in a position to make decisions autonomously because their healthcare provider will always know more than they do. However, they can at the same time be compliant with the paediatrician's recommendation, but claim the decision as their own anyway since it was guided by a trusted source with whom they have a good relationship. ${ }^{1}$ The theory has also been confirmed by other studies, ${ }^{57}$ which found that patients felt they 'owned' their decision when it was the one recommended by a trusted medical professional. Thus, to feel empowered does not necessarily mean that parents will always make decisions on their own. Having the ability to negotiate the extent to which one is involved in decision-making is key; in some instances, parents will be entirely guided by health professionals, in other situations it is a genuinely shared decision, and in yet others, entirely the decision of the parent. It is a wholly context-specific decision. ${ }^{48}$

Second, the vast majority of the participants found that autonomy was related to issues of responsibility and freedom, thus reinforcing the idea that autonomy is connected to 'morality, personhood and agency'. 'While only a small, educated minority was willing to assume the legal responsibility derived from making an autonomous choice, participants were equally split in their opinion regarding the morality of having the freedom to make the final decision. Previous studies found that adolescents' perspectives on their legal responsibility in relation to their vaccination might be a barrier to immunisation adherence. ${ }^{58}$ With respect to freedom of choice, studies also found that a small proportion of individuals are unlikely to vaccinate when immunisations are compulsory. ${ }^{59} 60$

A third major finding was that parents reported about their preferences regarding their vaccination-related information when asked about their understanding of autonomy and competence in the MMR vaccination decision. Participants distinguished themselves as active seekers, passive recipients or information avoiders. It is worth noting that most information avoiders and passive seekers also had lower educational levels. Research has previously found that those with more access to health-related information and better informationseeking skills are more likely to make informed medical decisions, ${ }^{61}$ and that information-seeking preferences can affect one's vaccination decision. ${ }^{49}$ Moreover, information orientation (engagement vs apprehension) has been found to predict one's objective and perceived ability to use information technology for health. ${ }^{62}$

A last finding relates to the empowerment subdimension of meaningfulness. When asked to compare the MMR vaccination decision to other decisions made for their child, the majority of the participants reported that it is something natural 'you just do', something that neither causes stress nor requires energy. These parents also reported that their MMR vaccination decision could have an impact not only on the health of their child but also on their community's health. A small minority, on the other hand, reported that deciding over MMR was a time-consuming, stressful task, which topped all other decisions. It is worth noting that these parents also lamented a poor relationship with the paediatrician. The idea that vaccination might be an obvious choice and a normal part of bringing up a child, and that it might require more or less thinking on the basis of its relative relevance, was also found in previous studies. 54954 


\section{Strengths and weaknesses of the study}

This is the first study to shed light on parents' understanding of empowerment in their MMR vaccination decision-making in a low MMR coverage area. Previous work has explored the construct of psychological empowerment in the MMR vaccination decision, ${ }^{5}$ suggesting the relevance of parental self-efficacy and selfdetermination in such a decisional context. The study is subject to a number of limitations. First, the self-selected nature of our sample might have resulted in focus group participants mainly being provaccination parents willing to share their compliance with the official immunisation recommendations. Second, recruiting through the vaccination centres might have prevented us from reaching those who are highly opposed to immunisations and who even refuse the DTaP vaccination. However, this could also be seen as a strength of the study, as a large number of our participants were not completely decided on whether to vaccinate or not. Third, due to a high dropout rate, the focus groups conducted in this study included only four to six participants each. While groups of six participants are generally the minimal recommended number in focus groups, discussion among the participants was not prevented by the limited sample size thanks to participants' diversity in their opinion. Furthermore, the research team that participated in the focus group was limited to two members (one facilitator and one recorder) when the size of the focus group was below six participants. Finally, since we extracted our results from qualitative reports of a small sample of parents, our findings cannot be generalised to a bigger population.

\section{Implications}

The findings have a number of implications both for theory and for practice. First, the construct of empowerment appears to be perceived by parents in the context of the MMR vaccination decision as more nuanced than our initial conceptualisation. While autonomy and competence are perceived as salient dimensions of the construct, they are strictly related to issues of freedom, responsibility, trust in the paediatrician, relevance of the decision and information orientation.

In terms of practice, it is worth noting that the large majority of participants reported as not making distinctions between vaccinations; therefore, our findings could be applied to multiple vaccinations. Since empowerment was viewed in different ways by our participants, ambiguous or extreme interpretations of the empowerment principles (such as autonomy) need to be avoided for all vaccinations as they might result in contract-like relationships between parents and health professionals, isolate parents with their responsibility of the decision, or curtail other possible immunisation solutions. ${ }^{63}$ Also, it should be noted that not all parents wish to be empowered in the same way. Some might need to be guided by the child's paediatrician to feel in control of their decision, by simply conforming to his/ her advice or the official recommendations and avoiding any other information sources. Others might highly value active information, seeking to feel competent, and finally make an autonomous decision. In all instances, as other studies found, ${ }^{48} 4964$ it should be recognised that paediatricians are key in parents' empowerment in the vaccination decision. Not only do they need to be perceived as competent professionals by parents, but they also have to build a trustworthy relationship with them. ${ }^{4}$ Furthermore, they should be willing to address parents' questions and concerns, make an effort to understand whether parents do or do not wish to share in the decision-making, recognise how their interactions and relationships with parents can either enable or impair parents' empowerment, and finally adapt their communication style accordingly. ${ }^{48} 4964$

\section{Future research}

Since a particular vaccination decision, the acceptance of the informed consent, or the attitude driving a given vaccination behaviour, may or may not be an expression of parental empowerment, ${ }^{1}$ future quantitative research has to clarify whether empowerment and its subdimensions can have an impact on the acceptance of vaccination recommendations. In this sense, developing appropriate measures of the empowerment construct in this particular context, and testing its relationship with other key variables such as vaccination knowledge and risk perception, would be a valuable step.

\section{CONCLUSIONS}

Parents' empowerment in the vaccination decision should be encouraged to serve parents' rather than institutional interests. ${ }^{65}$ Misconceived assumptions about empowerment might be a contributing factor to vaccine hesitancy and to health professionals' frustration about their potential to effectively cooperate with parents. ${ }^{63}$ If parents are asked to be empowered in the vaccination decision, it is important that this be correctly interpreted and implemented by best practice. In this sense, by overtly employing relational autonomy as a crucial element of the vaccination decision, empowerment in parental immunisation choice might become a more comprehensible and stronger principle, and could help paediatricians and other health professionals to genuinely promote and implement parents' autonomy. ${ }^{63}$ Health professionals can appeal to a principle of parent empowerment by facilitating parents' ability to make an informed and autonomous decision and, at the same time, by promoting their relational autonomy. ${ }^{63}$ This can be carried out by ensuring that parents are sufficiently informed, have the skills to find, assess and understand vaccination-related information by other sources, and by building a trustworthy relationship with them. On the other hand, a view of empowerment that isolates parents in their decision-making would not be in line with a patient-centred/parent-centred model. ${ }^{63}$ 
Furthermore, health authorities' risk communication should include a description of the reasons for restricting and expanding individual rights in a way to maximise comprehension, since there is evidence that informed consent does not always provide clear and useful information. ${ }^{66}{ }^{67}$ Trained staff (preventive medicine experts, vaccination nurses) should also be available in the vaccination centre, to encourage parent's relational autonomy and to answer questions. ${ }^{2}$

The advocated principle of parental empowerment in the vaccination decision in a context of voluntary participation, while suggesting that parental autonomy is central, does not mean that it is absolute. ${ }^{68}$

\section{Twitter Follow Marta Fadda at @martafadda}

Acknowledgements The authors would like to thank all the participants for devoting their time to participate in our study, and the Health Authorities of the Province of Trento for helping in the recruitment and for logistically supporting this study. They also thank llaria Mammolo for her help during and after the work with the focus groups. The authors are grateful to Professor Peter Salmon for his insightful suggestions on an early draft of the manuscript and to the Swiss National Science Foundation (SNSF) for financially supporting this study.

Contributors MF and EG participated in the design and implementation of the study, and the analysis of the data and its interpretation. VC and PJS participated in the design and implementation of the study. All the authors contributed to the drafting of the manuscript.

Funding This work was supported by the SNSF grant number FNS_147333. Competing interests None declared.

Patient consent Obtained

Ethics approval Ethical Committee for Clinical Trials of the Province of Trento (ID 54896583).

Provenance and peer review Not commissioned; externally peer reviewed.

Data sharing statement No additional data are available.

Open Access This is an Open Access article distributed in accordance with the Creative Commons Attribution Non Commercial (CC BY-NC 4.0) license, which permits others to distribute, remix, adapt, build upon this work noncommercially, and license their derivative works on different terms, provided the original work is properly cited and the use is non-commercial. See: http:// creativecommons.org/licenses/by-nc/4.0/

\section{REFERENCES}

1. Kukla R. Conscientious autonomy: displacing decisions in health care. Hastings Cent Rep 2005;35:34-44.

2. Woolley AP. Informed consent to immunization: the risks and benefits of individual autonomy. Calif Law Rev 1977;65:1286-314.

3. El Amin AN, Parra MT, Kim-Farley R, et al. Ethical issues concerning vaccination requirements. Public Health Rev 2012;34:1-20.

4. Haverkate M, D'Ancona F, Giambi C, et al. Mandatory and recommended vaccination in the EU, Iceland and Norway: results of the Venice 2010 survey on the ways of implementing national vaccination programmes. Euro Surveill 2012;17:pii: 20183.

5. Fadda M, Depping MK, Schulz PJ. Addressing issues of vaccination literacy and psychological empowerment in the measles-mumps-rubella (MMR) vaccination decision-making: a qualitative study. BMC Public Health 2015;15:836.

6. Favin $\mathrm{M}$, Steinglass $\mathrm{R}$, Fields $\mathrm{R}$, et al. Why children are not vaccinated: a review of the grey literature. Int Health 2012;4:229-38.

7. Betsch $\mathrm{C}$, Wicker S. E-health use, vaccination knowledge and perception of own risk: drivers of vaccination uptake in medica students. Vaccine 2012;30:1143-8.
8. Bennett P, Smith C. Parents attitudinal and social influences on childhood vaccination. Health Educ Res 1992;7:341-8.

9. Bond L, Nolan T, Pattison P, et al. Vaccine preventable diseases and immunisations: a qualitative study of mothers' perceptions of severity, susceptibility, benefits and barriers. Aust $N Z J$ Public Health 1998;22:441-6.

10. Tarrant M, Thomson N. Secrets to success: a qualitative study of perceptions of childhood immunisations in a highly immunised population. J Paediatr Child Health 2008;44:541-7.

11. Spier RE. Perception of risk of vaccine adverse events: a historical perspective. Vaccine 2001;20:78-84.

12. Brown KF, Shanley R, Cowley NA, et al. Attitudinal and demographic predictors of measles, mumps and rubella (MMR) vaccine acceptance: development and validation of an evidence-based measurement instrument. Vaccine 2011;29:1700-9.

13. Heininger U. An internet-based survey on parental attitudes towards immunization. Vaccine 2006;24:6351-5.

14. Yaqub $\mathrm{O}$, Castle-Clarke $\mathrm{S}$, Sevdalis $\mathrm{N}$, et al. Attitudes to vaccination: a critical review. Soc Sci Med 2014;112:1-11.

15. Lavail $\mathrm{KH}$, Kennedy AM. The role of attitudes about vaccine safety, efficacy, and value in explaining parents' reported vaccination behavior. Health Educ Behav 2013;40:544-51.

16. Gilkey MB, Magnus BE, Reiter PL, et al. The Vaccination Confidence Scale: a brief measure of parents' vaccination beliefs. Vaccine 2014;32:6259-65.

17. Bardenheier B, Yusuf $H$, Schwartz B, et al. Are parental vaccine safety concerns associated with receipt of measles-mumps-rubella, diphtheria and tetanus toxoids with acellular pertussis, or hepatitis $B$ vaccines by children? Arch Pediatr Adolesc Med 2004;158:569-75.

18. Andreae MC, Freed GL, Katz SL. Safety concerns regarding combination vaccines: the experience in Japan. Vaccine 2004;22:3911-16.

19. Streefland $\mathrm{PH}$. Public doubts about vaccination safety and resistance against vaccination. Health Policy 2001;55:159-72.

20. Cooper LZ, Larson HJ, Katz SL. Protecting public trust in immunization. Pediatrics 2008;122:149-53.

21. Austin H, Campion-Smith $\mathrm{C}$, Thomas $\mathrm{S}$, et al. Parents' difficulties with decisions about childhood immunisation. Community Pract 2008;81:32-5

22. Mills $E$, Jadad AR, Ross $C$, et al. Systematic review of qualitative studies exploring parental beliefs and attitudes toward childhood vaccination identifies common barriers to vaccination. J Clin Epidemiol 2005;58:1081-8.

23. Larson $\mathrm{HJ}$, Smith DMD, Paterson $\mathrm{P}$, et al. Measuring vaccine confidence: analysis of data obtained by a media surveillance system used to analyse public concerns about vaccines. Lancet Infect Dis 2013;13:606-13.

24. Larson HJ, Wilson R, Hanley S, et al. Tracking the global spread of vaccine sentiments: the global response to Japan's suspension of its HPV vaccine recommendation. Hum Vaccin Immunother 2014;10:2543-50.

25. Larson $\mathrm{H}$, Leask J, Aggett $\mathrm{S}$, et al. A multidisciplinary research agenda for understanding vaccine-related decisions. Vaccines (Basel) 2013;1:293-304.

26. Oraby T, Thampi V, Bauch CT. The influence of social norms on the dynamics of vaccinating behaviour for paediatric infectious diseases. Proc Biol Sci 2014;281:20133172.

27. [No authors listed]. Patient empowerment-who empowers whom? Lancet 2012;379:1677.

28. Zimmerman MA. Psychological empowerment: issues and illustrations. Am J Community Psychol 1995;23:581-99.

29. Spreitzer GM. Psychological empowerment in the workplace: dimensions, measurement, and validation. Acad Manag J 1995;38:1442-65.

30. Spreitzer GM. Social structural characteristics of psychological empowerment. Acad Manag J 1996;39:483-504.

31. Florian V, Elad D. The impact of mothers' sense of empowerment on the metabolic control of their children with juvenile diabetes. $J$ Pediatr Psychol 1998;23:239-47.

32. Davison BJ, Degner LF. Empowerment of men newly diagnosed with prostate cancer. Cancer Nurs 1997;20:187-96.

33. Mishra SI, Chavez LR, Magaña JR, et al. Improving breast cancer control among Latinas: evaluation of a theory-based educational program. Health Educ Behav 1998;25:653-70.

34. Tsay S-L, Hung L-O. Empowerment of patients with end-stage renal disease-a randomized controlled trial. Int J Nurs Stud 2004:41:59-65.

35. Cornell Empowerment Group. Empowerment and family support. Networking Bull 1989;1:2

36. Akey TM, Marquis JG, Ross ME. Validation of scores on the psychological empowerment scale: a measure of empowerment for 
parents of children with a disability. Educ Psychol Meas 2000;60:419-38.

37. Nassar-McMillan SC, Wyer M, Oliver-Hoyo M, et al. Using focus groups in preliminary instrument development: expected and unexpected lessons learned. Qual Rep 2010;15: 1621-34.

38. Maisonneuve $\mathrm{H}$, Floret $\mathrm{D}$. Wakefield's affair: 12 years of uncertainty whereas no link between autism and MMR vaccine has been proved. Presse Med 2012;41(Pt 1):827-34.

39. Centers for Diseases Control and Prevention (CDC). Vaccines. http://www.cdc.gov/vaccines/vpd-vac/measles/faqs-dis-vac-risks.htm (accessed 19 Mar 2015).

40. Dannetun E, Tegnell A, Hermansson G, et al. Timeliness of MMR vaccination-influence on vaccination coverage. Vaccine 2004;22:4228-32.

41. Italian Ministry of Health. Pediatric vaccinations in Italy: vaccination coverage, 2014. http://www.salute.gov.it/imgs/C_17_tavole_20_ allegati_iitemAllegati_2_fileAllegati_itemFile_0_file.pdf (accessed 4 Dec 2015).

42. Italian Ministry of Health. Vaccination schedule. http://www.salute. gov.it/portale/temi/p2_6.jsp?lingua=italiano\&id=648\&area=Malattie $\%$ 20infettive\&menu=vaccinazioni (accessed 9 Feb 2016).

43. Zingg A, Siegrist M. Measuring people's knowledge about vaccination: developing a one-dimensional scale. Vaccine 2012;30:3771-7.

44. Guest G. How many interviews are enough? An experiment with data saturation and variability. Field Methods 2006;18:59-82.

45. Braun V, Clarke V. Using thematic analysis in psychology. Qual Res Psychol 2006;3:77-101.

46. Italian National Institute of Statistics (Istat). Socio-demographic indicators, 2015. http://www.istat.it/it/archivio/149003 (accessed 15 Feb 2016).

47. McMurray R, Cheater FM, Weighall A, et al. Managing controversy through consultation: a qualitative study of communication and trust around MMR vaccination decisions. $\mathrm{Br} J$ Gen Pract 2004;54:520-5.

48. Jackson C, Cheater FM, Reid I. A systematic review of decision support needs of parents making child health decisions. Health Expect 2008;11:232-51.

49. Gust DA, Darling N, Kennedy A, et al. Parents with doubts about vaccines: which vaccines and reasons why. Pediatrics 2008;122:718-25.

50. Opel DJ, Heritage J, Taylor JA, et al. The architecture of provider-parent vaccine discussions at health supervision visits. Pediatrics 2013;132:1037-46.

51. Taylor JA, Darden PM, Slora E, et al. The influence of provider behavior, parental characteristics, and a public policy initiative on the immunization status of children followed by private pediatricians: a study from Pediatric Research in Office Settings. Pediatrics 1997:99:209-15.
52. Kennedy A, Basket M, Sheedy K. Vaccine attitudes, concerns, and information sources reported by parents of young children: results from the 2009 HealthStyles survey. Pediatrics 2011;127:S92-9.

53. Kennedy A, Lavail K, Nowak G, et al. Confidence about vaccines in the United States: understanding parents' perceptions. Health Aff (Millwood) 2011;30:1151-9.

54. Austvoll-Dahlgren A, Helseth S. What informs parents' decision-making about childhood vaccinations? J Adv Nurs 2010;66:2421-30.

55. Mergler MJ, Omer SB, Pan WK, et al. Association of vaccine-related attitudes and beliefs between parents and health care providers. Vaccine 2013;31:4591-5

56. Entwistle VA, Carter SM, Cribb A, et al. Supporting patient autonomy: the importance of clinician-patient relationships. J Gen Intern Med 2010;25:741-5.

57. Mendick N, Young B, Holcombe C, et al. The ethics of responsibility and ownership in decision-making about treatment for breast cancer: triangulation of consultation with patient and surgeon perspectives. Soc Sci Med 2010;70:1904-11.

58. Ford CA, English A, Davenport AF, et al. Increasing adolescent vaccination: barriers and strategies in the context of policy, legal, and financial issues. $J$ Adolesc Health 2009;44:568-74.

59. Kennedy AM, Brown CJ, Gust DA. Vaccine beliefs of parents who oppose compulsory vaccination. Public Health Rep 2005;120:252-8.

60. Seale H, Leask J, Macintyre CR. Do they accept compulsory vaccination? Awareness, attitudes and behaviour of hospital health care workers following a new vaccination directive. Vaccine 2009;27:3022-5.

61. Viswanath K, Finnegan JR. The knowledge gap hypothesis: twenty-five years later. In: Burleson B. Communication yearbook. Vol. 19. Thousand Oaks, CA: Sage, 1996:187-227.

62. Strekalova YA. Seekers and avoiders: using health information orientation to explore audience segmentation. $J$ Commun Healthc 2014;7:228-37.

63. Ells C, Hunt MR, Chambers-Evans J. Relational autonomy as an essential component of patient-centered care. Int J Fem Approaches Bioeth 2011:4:79-101.

64. Leask J, Kinnersley P, Jackson C, et al. Communicating with parents about vaccination: a framework for health professionals. BMC Pediatr 2012;12:154.

65. Salmon P, Hall GM. Patient empowerment or the emperor's new clothes. J R Soc Med 2004;97:53-6.

66. Attena F, Valdes Abuadili A, Marino S. The informed consent in Southern Italy does not adequately inform parents about infant vaccination. BMC Public Health 2014;14:211.

67. Salmon DA, Omer SB. Individual freedoms versus collective responsibility: immunization decision-making in the face of occasionally competing values. Emerg Themes Epidemiol 2006;3:13.

68. Verweij M, Dawson A. Ethical principles for collective immunisation programmes. Vaccine 2004:22:3122-6. 